\title{
Finite element modeling of thermo-active diaphragm walls
}

\author{
Yi RUI ${ }^{\mathrm{a}}$, Mei YIN ${ }^{\mathbf{b} *}$ \\ ${ }^{a}$ Centre for Smart Infrastructure and Construction, Department of Engineering, University of Cambridge, Cambridge, CB3 OFA, UK \\ ${ }^{b}$ Civil and Environmental Engineering Department, Brunel Univisity, London UB8 3PH, UK \\ *Corresponding author. E-mail: myin0915@gmail.com
}

(C) The Author(s) 2020. This article is published with open access at link.springer.com and journal.hep.com.cn

\begin{abstract}
There are two major challenges faced by modern society: energy security, and lowering carbon dioxide gas emissions. Thermo-active diaphragm walls have a large potential to remedy one of these problems, since they are a renewable energy technology that uses underground infrastructure as a heat exchange medium. However, extensive research is required to determine the effects of cyclic heating and cooling on their geotechnical and structural performance. In this paper, a series of detailed finite element analyses are carried out to capture the fully coupled thermohydro-mechanical response of the ground and diaphragm wall. It is demonstrated that the thermal operation of the diaphragm wall causes changes in soil temperature, thermal expansion/shrinkage of pore water, and total stress applied on the diaphragm wall. These, in turn, cause displacements of the diaphragm wall and variations of the bending moments. However, these effects on the performance of diaphragm wall are not significant. The thermally induced bending strain is mainly governed by the temperature differential and uneven thermal expansion/shrinkage across the wall.
\end{abstract}

KEYWORDS thermo-active diaphragm wall, finite element analysis, thermo-hydro-mechanical coupling, ground source heat pump

\section{Introduction}

Two of the major challenges faced by modern society are the depletion of finite non-renewable energy resources and increased carbon dioxide gas concentrations in the Earth's atmosphere. The current focus of government policy (UK regulations: 2008 Climate Change Act) and the construction industry to reduce energy usage and the carbon footprint of both new and existing construction has led to an increased uptake in innovative new technologies to reduce the impact of construction on climate change. One of the technologies which can cause a significant reduction in energy requirements is ground source heat pumps (GSHP) and their application within energy foundations such as thermo-active piles and diaphragm walls. GSHP is a well-established and cost-effective renewable technology for heating and cooling. It can also be integrated within the structural elements of a building like piles, diaphragm walls, raft foundations, tunnel linings, etc. By installing the primary circuit (absorber pipes) within the foundations, they become thermo-active and provide both load-bearing

Article history: Received Sep 26, 2018; Accepted Jan 4, 2019 support and energy for the building. The first examples of such systems date to the 1980 s, with the first thermo-active piles and walls being installed in Austria and Switzerland in 1984 and 1996, respectively [1]. Thermo-active foundations have gained popularity within the UK over the past 10 years, with thermo-active piles being installed at Keble College in Oxford in 2001 [2], Paddington Building and Lambeth College in London in 2007 [3]. The first thermo-active diaphragm wall in the UK was installed at the Bulgari Hotel [4] in London in 2010, triggering a boost in the implementation of such systems in other projects.

A large number of studies have been performed investigating the effects of the operation of the thermoactive piles on the structural performance of the foundations [5-20]. Some other work focuses on the coupled thermo-hydro-mechanical behavior of energy storage [21]. On the other hand, a thermo-active diaphragm wall is different from a thermo-active pile because the pile is surrounded by the soil, whereas only one side of the wall is exposed to the soil. Current studies on the coupled thermo-mechanical behavior of thermo-active diaphragm walls are very limited. Bourne-Webb et al. [8] performed a 
numerical analysis of a thermo-active diaphragm wall. The results showed that thermally induced mechanical responses of the diaphragm wall are dominated by seasonal temperature changes, and that their magnitude is dependent on the ratio of the coefficient of thermal expansion of the concrete and that of the surrounding ground. Sterpi et al. [22] investigated the energy performance and mechanical responses of thermo-active diaphragm walls by finite element thermo-mechanical analyses. It was shown that the thermally induced internal axial forces and bending moments are not negligible. In addition, the magnitude of these mechanical responses depends also on the level of constraints the diaphragm wall is subjected to. Rui and Yin [23] investigated the wall-soil interaction behavior of a thermo-active diaphragm wall by conducting a thermo-hydro-mechanical (THM) coupling analysis. The GSHP operation makes the wall move in a cyclic manner, caused by two factors: the thermally induced deformation of the diaphragm wall itself, and the volume change of the soil and pore water. On the other hand, it was found that the thermal effect due to the seasonal changes in earth pressures acting on the diaphragm wall is neglected. Hence, the thermally induced bending moment of the diaphragm wall is mainly caused by the thermal differential across the wall.

This paper follows the work by Rui and Yin [19], which focused on the discussion of pile-soil interaction under both thermal and mechanical loading. In the present paper, this issue is explored further by thermo-hydro-mechanical coupling finite element analysis (FEA). The objective is to examine the impact of a limited set of thermo-mechanical parameters (soil permeability coefficient, soil heat transfer coefficient, and pile thermal expansion coefficient), and to put these results into context in terms of the current understanding of the coupled thermo-hydro-mechanical behavior of thermo-active diaphragm walls, which adds value to the design of thermo-active diaphragm walls.

\section{Basis for FEA}

\subsection{Thermo-active diaphragm wall}

The numerical analysis is based on a thermo-active diaphragm wall installed at an underground metro station in London, as shown in Fig. 1. The station box was constructed using the 'bottom up' method. The $1 \mathrm{~m}$ thick diaphragm wall (up to $41 \mathrm{~m}$ depth) was first installed by excavating a trench to a required depth. The absorber pipes were attached to the reinforcement cage and lowered into the trench, where concrete was poured in to cast the diaphragm wall. The soil was excavated $29 \mathrm{~m}$ deep and temporary props were added to support the excavation. Slabs were cast from the bottom and work proceeded upwards, replacing props with slabs to form five levels for the station box. The box side is $16 \mathrm{~m}$ wide and $29 \mathrm{~m}$ deep, and the diaphragm wall is $1 \mathrm{~m}$ wide and $41 \mathrm{~m}$ deep. The absorber pipe is embedded in the diaphragm wall, $0.25 \mathrm{~m}$

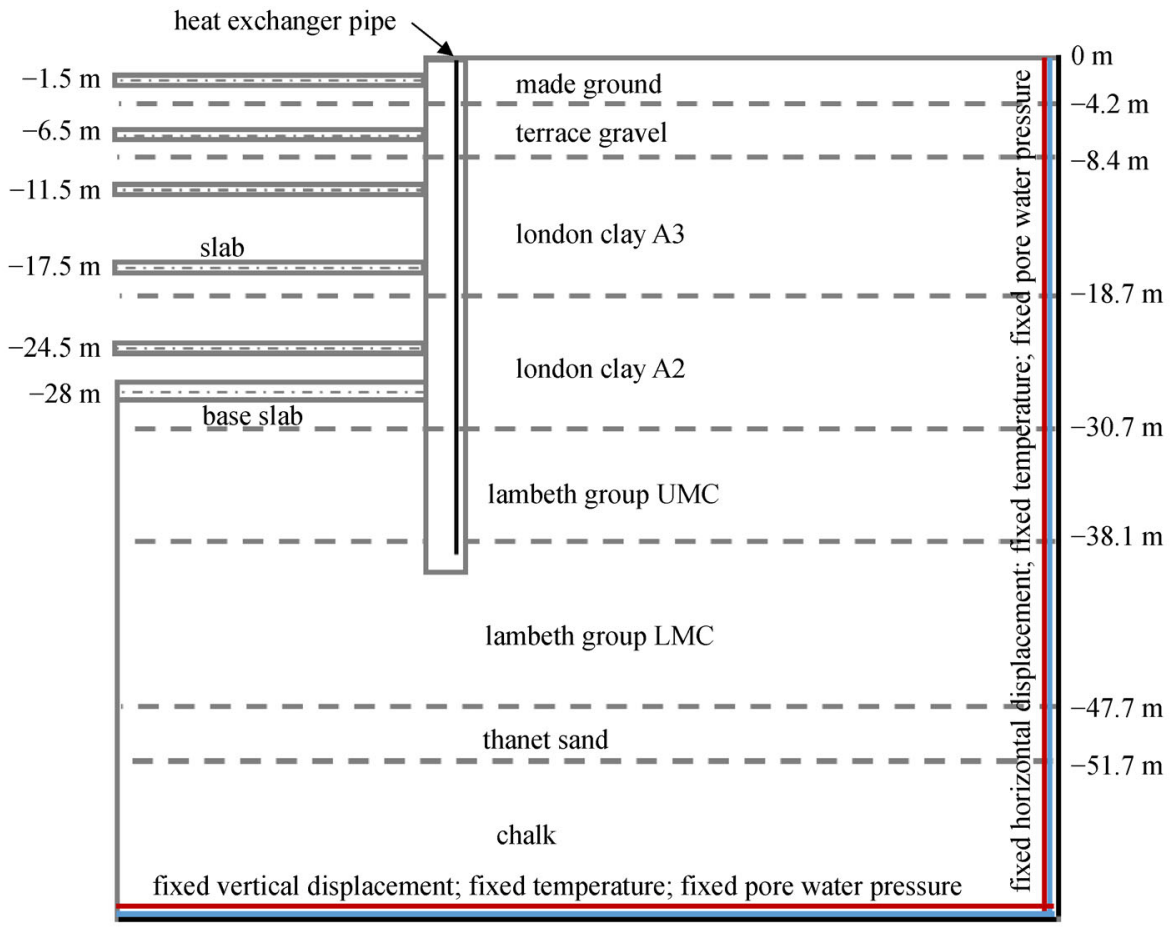

Fig. 1 Geometry and boundary conditions of the diaphragm wall. 
toward the unexcavated side.

Three types of boundary condition must be assigned in the THM coupling simulation: displacement, pore pressure, and temperature boundary conditions. On the righthand-side (RHS) vertical boundaries, a roller boundary condition was applied so that horizontal displacement was not permitted. At the base of the model, displacement was restricted in the vertical direction. Fixed pore pressure boundary conditions were applied at the RHS and base boundary, which acted as free drainage surfaces in the model. It was assumed that the water table was located at the ground surface and exhibited hydrostatic behavior with depth. Additionally, the temperature at the RHS and base boundary was kept at the initial value. The pipe network and the circulating flow were not simulated. Instead, the temperature of the pipe circuit was set as variable nodal values in the FEA to simulate the operation of the GSHP.

To accurately model the construction sequence, a series of construction stages were simulated as closely as possible to match the design construction sequence. In addition, the seasonal operation of the thermo-active diaphragm wall was split into two six-month cycles annually: a six-month winter station heating (soil cooling) cycle and a six-month summer station recharge (soil heating) cycle, as shown in Fig. 2. The seasonal operation was modeled over a 20 -year operational life of 20 pairs of cycles. During the winter cycle the station air was heated to maintain the optimal temperature. To maintain this, the GSHP primary circuit pumped fluid at $2^{\circ} \mathrm{C}$ through the pipe in the diaphragm wall. The model essentially kept the temperature of the heat exchanger pipe at $2{ }^{\circ} \mathrm{C}$ throughout the cycle. During summer the GSHP was put into a recharge state, where to maintain the temperature within the station at $18^{\circ} \mathrm{C}$, the primary circuit was essentially switched off. This was achieved in the model by holding the heat exchanger pipe at $18^{\circ} \mathrm{C}$ throughout the cycle.

\subsection{Mechanics of THM coupled processes}

Heat transfer mechanisms in soil are complex due to its multi-phase nature, and include conduction, convection, radiation vaporization and condensation, ion exchange and freeze-thawing processes [1]. However, for the thermoactive diaphragm walls project only conduction and convection are considered as they contribute the most toward heat transfer in soil. Hence, the governing equation of heat transfer in the soil can be written as:

$$
-\sum_{i=1}^{3} \lambda \frac{\partial T}{\partial x_{i}^{2}}+C_{\mathrm{w}} \sum_{i=1}^{3} q_{i} \frac{\partial T}{\partial x_{i}}+C_{\mathrm{s}} \frac{\mathrm{d} T}{\mathrm{~d} t}=0,
$$

where $\lambda$ is the heat conductivity, $T$ is the temperature, $C_{\mathrm{s}}$, $C_{\mathrm{w}}$ are the volumetric heat capacity of soil and water, respectively, and $q_{i}$ is the water flow flux, subscript $i$ indicates the direction of the vector.

In this study, the pore fluid is considered to be compressible, and is assumed to follow Darcy's Law:

$$
q_{i}=\frac{k_{\mathrm{S}}}{\gamma_{\mathrm{w}}}\left(\frac{\partial p}{\partial x_{i}}-\rho_{\mathrm{w}} g_{i}\right)
$$

where $k_{\mathrm{S}}$ is the permeability coefficient $(\mathrm{m} / \mathrm{s}), \gamma_{\mathrm{w}}$ is the unit weight of water, is the pore pressure, $\rho_{\mathrm{w}}$ is the density of water, and $g_{i}$ is the gravity, which has three components $\left(g_{1}=0 \mathrm{~N} / \mathrm{kg}, g_{2}=0 \mathrm{~N} / \mathrm{kg}, g_{3}=-9.8 \mathrm{~N} / \mathrm{kg}\right)$.

The mass conservation between volumetric strain and water drainage leads to the following storage equation:

$$
\sum_{i=1}^{3} \frac{\partial q_{i}}{\partial x_{i}}-\frac{\mathrm{d}}{\mathrm{d} t} \varepsilon_{\mathrm{vol}}-\frac{n \mathrm{~d} p}{k_{\mathrm{w}} \mathrm{d} t}+3 \cdot n \alpha_{\mathrm{w}} \frac{\mathrm{d} T}{\mathrm{~d} t}=0,
$$

where $\alpha_{\mathrm{w}}$ is the linear coefficient of thermal expansion of water, $n$ is the porosity, $k_{\mathrm{w}}$ is the bulk modulus of the pore water, and $\varepsilon_{\mathrm{vol}}$ is the volumetric strain of the soil skeleton.

The stress equilibrium equation can be written as:

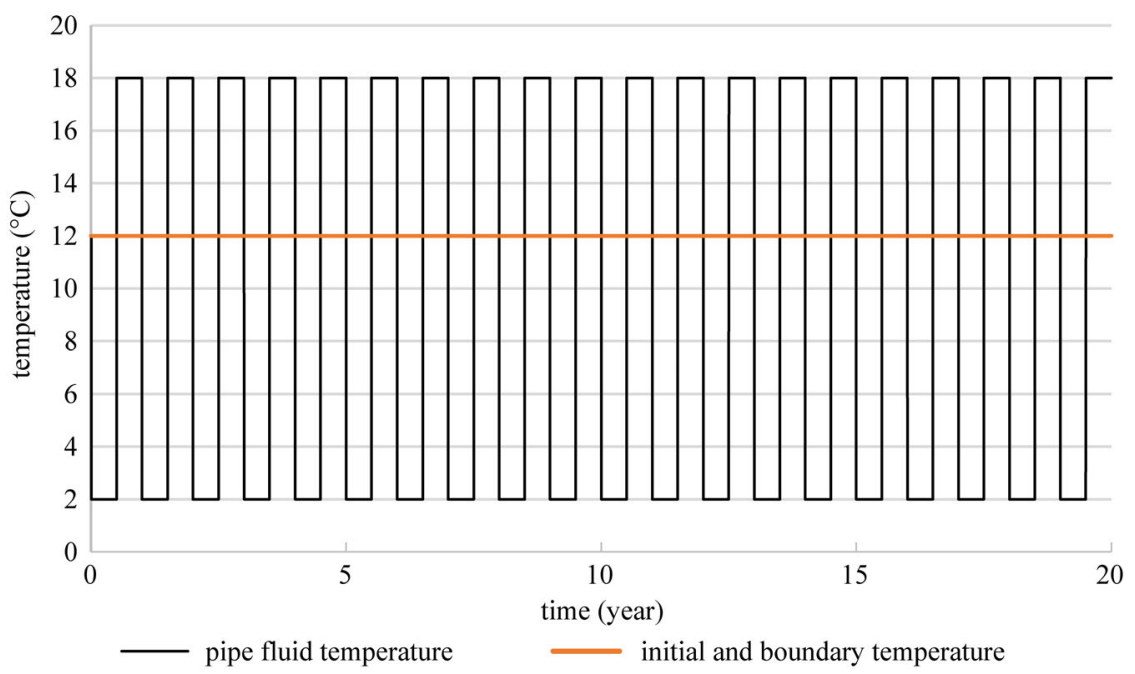

Fig. 2 Thermal boundary condition. 


$$
\frac{\partial\left(\sigma_{j i}^{\prime}+p I_{j i}\right)}{\partial x_{j}}+\rho_{\mathrm{sw}} g_{i}=0,
$$

where $\sigma_{j i}^{\prime}$ is the effective stress, $\rho_{\mathrm{sw}}$ is the density of saturated soil, and $I_{j i}$ is the component of the identity tensor.

In this model, the soil is assumed to be isotropic, and that the temperature variation induces volume variations of the soil skeleton,

$$
\mathrm{d} \varepsilon_{\mathrm{vol}}=\frac{\mathrm{d} p^{\prime}}{K_{\mathrm{S}}}+3 \cdot \alpha_{\mathrm{S}} \cdot \mathrm{d} T
$$

where $K_{\mathrm{S}}$ is the bulk moduli of the soil skeleton, $\alpha_{\mathrm{S}}$ is the linear coefficient of thermal expansion of the soil skeleton, $\varepsilon_{\mathrm{vol}}$ is the elastic volumetric strain, and $p^{\prime}$ is the mean effective stress.

In the diaphragm wall, the pore fluid water doesn't exit. Hence, only thermos-mechanical coupling is considered. Equation (1) can be simplified as,

$$
\sum_{i=1}^{3} \lambda \frac{\partial \mathrm{T}}{\partial x_{i}^{2}}+C_{\mathrm{C}} \frac{\mathrm{d} T}{\mathrm{~d} t}=0
$$

where $C_{\mathrm{C}}$ are the volumetric heat capacity of soil.

Equation (4) can be simplified as,

$$
\frac{\partial \sigma_{j i}}{\partial x_{j}}+\rho_{C} g_{i}=0
$$

where $\rho_{\mathrm{C}}$ is the density of concrete, and Eq. (5) can be simplified as,

$$
\mathrm{d} \varepsilon_{\mathrm{vol}}=\frac{\mathrm{d} p}{K_{\mathrm{c}}}+3 \cdot \alpha_{\mathrm{c}} \cdot \mathrm{d} T,
$$

where $K_{\mathrm{c}}$ is the bulk moduli of the soil concrete, $\alpha_{\mathrm{c}}$ is the linear coefficient of thermal expansion of the concrete.

The Mohr-Coulomb failure criterion is used in this study, which assumes that failure occurs when the shear stress reaches a value that depends linearly on the normal stress as defined in Eq. (9). The material constant $C$ defines the cohesion yield stress for the hardening behavior of the material, and the friction angle $\phi$ controls the shape of the yield surface in the deviatoric plane.

$$
f=\sigma_{1}-\sigma_{3} N_{\phi}+2 C \sqrt{N_{\phi}}=0,
$$

where $\sigma_{1}$ and $\sigma_{3}$ are the principal stresses, $C$ is the cohesion.

$$
N_{\phi}=\frac{1+\sin \phi}{1-\sin \phi},
$$

where $\phi$ is the friction angle.

The plastic potential function can be written as,

$$
\begin{gathered}
g=\sigma_{1}-\sigma_{3} N_{\Psi}, \\
N_{\Psi}=\frac{1+\sin \Psi}{1-\sin \Psi},
\end{gathered}
$$

where $\Psi$ is the dilation angle.

The thermo-active diaphragm wall analysis treats soil as a fully saturated multi-phase continuum, which is characterized by the elastic-plastic Mohr-Coulomb soil model. All the parameters used in the soil model are listed in Table 1, where $G$ is the shear modulus and $v$ is the Poisson's ratio. The diaphragm is assumed to be linear elastic. The parameters for the Mohr-Coulomb model were selected based on Crossrail's design guideline. In addition, the linear coefficient of thermal expansion (CTE) of soil skeleton $\alpha_{\mathrm{S}}$ and concrete $\alpha_{\mathrm{C}}$ is assumed to be $10 \mu \varepsilon /{ }^{\circ}$. This value is close to the value suggested by Bourne-Webb et al. $[5,7]$. The CTE of pore water $\alpha_{\mathrm{w}}$ is $70 \mu \varepsilon /^{\circ}$, the porosity $n$ in this case study is assumed 0.3 , and other thermal properties about $C_{\mathrm{sw}}$ and $\lambda$ are from Rui and Yin [19,23], Rui et al. [24], Rui and Soga [20].

\begin{tabular}{|c|c|c|c|c|c|c|c|c|c|}
\hline soil layer & $G(\mathrm{kPa})$ & $\phi\left(^{\circ}\right)$ & $c(\mathrm{kPa})$ & $v$ & $\Psi\left(^{\circ}\right)$ & $\lambda\left(\mathrm{W} / \mathrm{m}^{2} \cdot \mathrm{K}\right)$ & $C\left(\mathrm{~kJ} / \mathrm{m}^{3} \cdot \mathrm{K}\right)$ & $\alpha\left(\mu \varepsilon /^{\circ}\right)$ & $k(\mathrm{~m} / \mathrm{S})$ \\
\hline$\overline{\text { made ground }}$ & 4000 & 22.2 & 0 & 0.2 & 0 & 1.25 & 2800 & 10 & $1 \times 10^{-4}$ \\
\hline terrace gravel & 20000 & 35.8 & 0 & 0.2 & 0 & 1.8 & 2800 & 10 & $1 \times 10^{-4}$ \\
\hline London clay A3 & 32000 & 25 & 5 & 0.2 & 0 & 1.6 & 3200 & 10 & $1 \times 10^{-10}$ \\
\hline London clay A2 & 42000 & 25 & 5 & 0.2 & 0 & 1.6 & 3200 & 10 & $1 \times 10^{-10}$ \\
\hline Lambeth group UMC & 125000 & 28 & 10 & 0.2 & 0 & 2.1 & 3200 & 10 & $1 \times 10^{-10}$ \\
\hline Lambeth group LMC & 112000 & 23 & 10 & 0.2 & 0 & 2.1 & 3200 & 10 & $1 \times 10^{-10}$ \\
\hline Thanet sand & 167000 & 27 & 0 & 0.2 & 0 & 1.27 & 2800 & 10 & $1 \times 10^{-6}$ \\
\hline chalk & 167000 & 32 & 0 & 0.2 & 0 & 1.27 & 2400 & 10 & $1 \times 10^{-6}$ \\
\hline concrete & 16700000 & - & - & - & - & 1.4 & 2400 & 10 & - \\
\hline
\end{tabular}

A series of finite element analyses was performed in order to investigate the effects of the thermo-hydromechanical properties, including heat conductivity, the permeability coefficient of soil, and the thermal expansion coefficient of the diaphragm wall. All the analyses presented in this paper are summarized in Table 2. The purpose of these parametric studies is to identify the

Table 1 Properties of soils 
Table 2 List of analyses

\begin{tabular}{lcc}
\hline ID & parametric study & assumed soil properties \\
\hline A & original value & Table 1 \\
B1 & heat conductivity of soil $\lambda$ & $\lambda \times 0.5$ \\
B2 & heat conductivity of soil $\lambda$ & $2.0 \lambda \times 2.0$ \\
C1 & permeability coefficient of soil $k$ & $k \times 0.2$ \\
C2 & permeability coefficient of soil $k$ & $5.0 k \times 5.0$ \\
D1 & thermal expansion coefficient of concrete $\alpha_{\text {con }}$ & $\alpha_{\text {con }} \times 0$ \\
D2 & thermal expansion coefficient of concrete $\alpha_{\text {con }}$ & $\alpha_{\text {con }} \times 4.0$ \\
\hline
\end{tabular}

parameters that may potentially be critical to the performance of the thermo-active diaphragm wall.

To validate the model, the construction induced horizontal movements of the diaphragm wall were simulated and compared to the monitoring data, as shown in Fig. 3. The movements are zeroed at the root of the wall. This is because the model was calibrated to the actual movement to the wall where the inclinometer measurements were made from the bottom of the wall. The results show that the monitoring data matched well with the simulation data. After excavated to $111.9 \mathrm{~m}$, the maximum difference is about $3 \mathrm{~mm}$, but the shape of the displacement distribution is very similar. This indicates that the stiffness is a little underestimated. In the next two steps, the maximum difference reduces to about $1 \mathrm{~mm}$. The good match between monitoring data and simulation data validates the mechanical properties used in this model, and hence give more confidence to perform thermo-hydromechanical analysis afterwards.

\section{Results and discussions}

\subsection{Effects of thermal conductivity}

Thermal conductivity is one of the most significant thermal properties of soil. In this paper, thermal conductive values vary from half the original value to twice the original value. As shown in Fig. 4, the temperature distribution within the soil is strongly affected by its thermal conductivity. In analysis B1, the thermally influenced

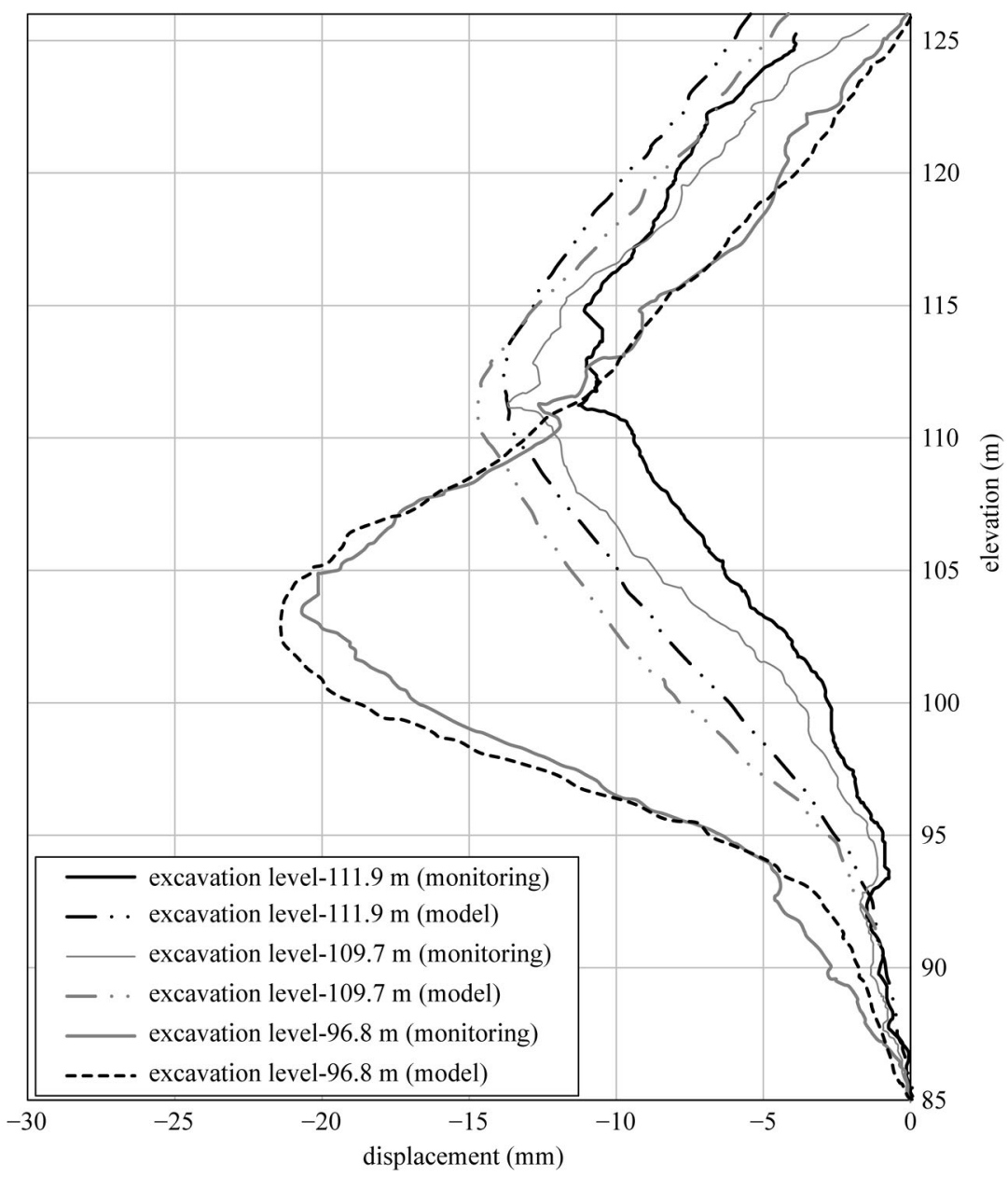

Fig. 3 Comparison of the relative horizontal movements between the monitoring data and FEA during construction. 

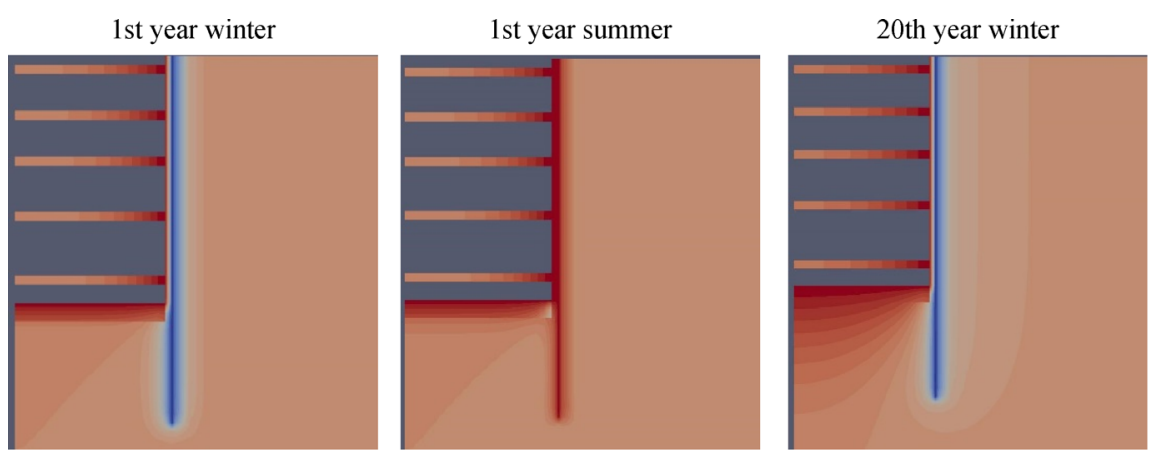

(a)
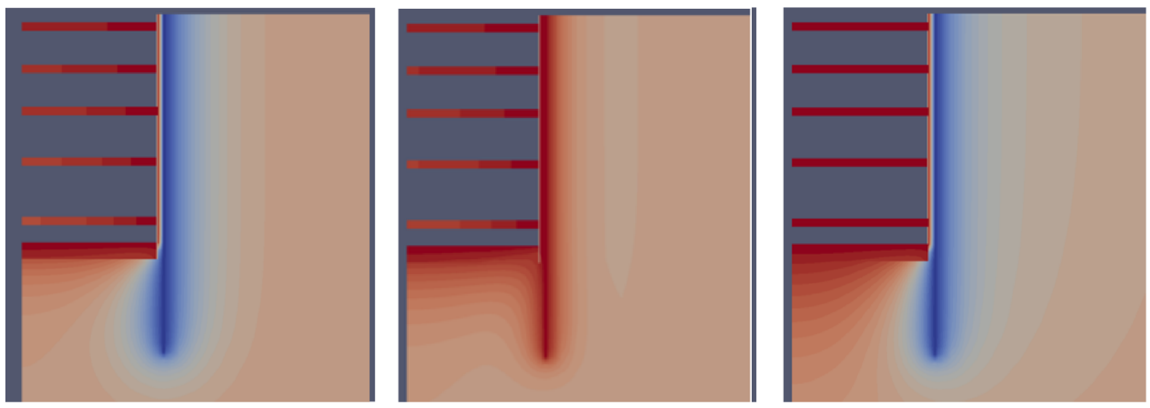

(b)
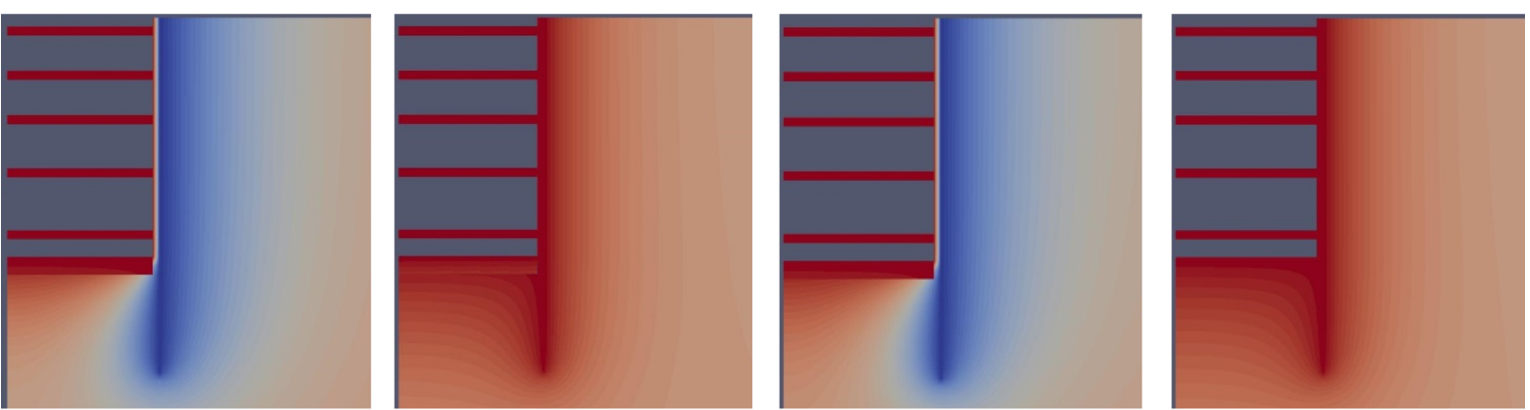

(c)

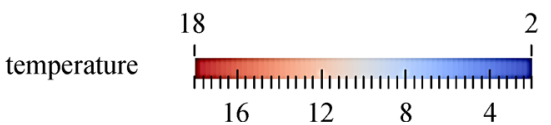

Fig. 4 Temperature distribution with variations in the thermal conductivity of the soil (unit: ${ }^{\circ} \mathrm{C}$ ): (a) analysis $\mathrm{B} 1: \lambda \times 0.5$; (b) analysis A: original value; (c) analysis B2: $\lambda \times 2$.

zone was localized in the soil adjacent to the diaphragm wall. But this zone became larger as the thermal conductivity increased. A similar phenomenon happened below the base slab, where more soil was heated in both winter and summer since the inside of the underground station was assumed to be hot all year due to the heat generated by the trains.

Figure 5 shows the horizontal total stress applied to the diaphragm wall on the unexcavated side. A change of total stress between the winter cycle and the summer cycle was observed, especially under the base slab, which was mainly determined by thermally induced expansion/shrinkage in the soil. With higher thermal conductivity, more soil was influenced by the temperature change, and thus more expansion/shrinkage was caused by heating and cooling. The total stress in the summer increased more when the thermal conductivity was higher, and thus the seasonal change in total stress between winter and summer cycle 


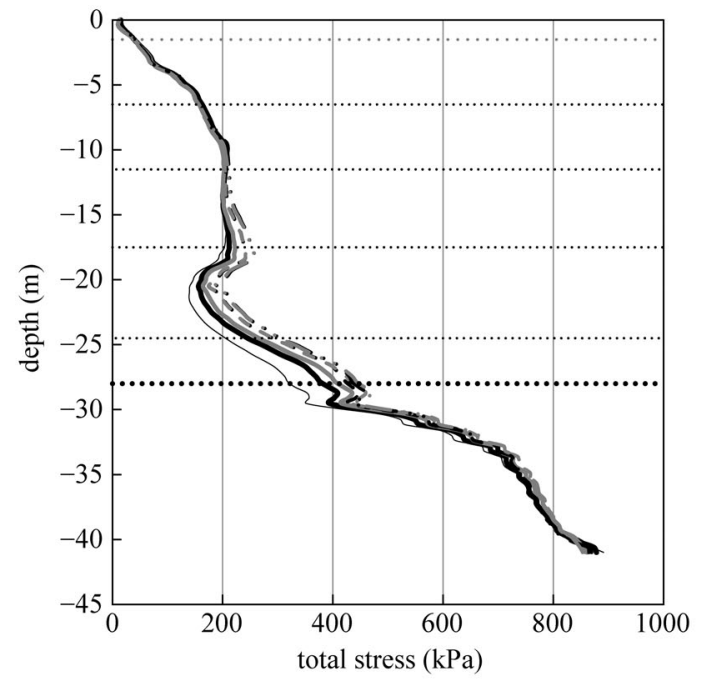

(a)



(c)

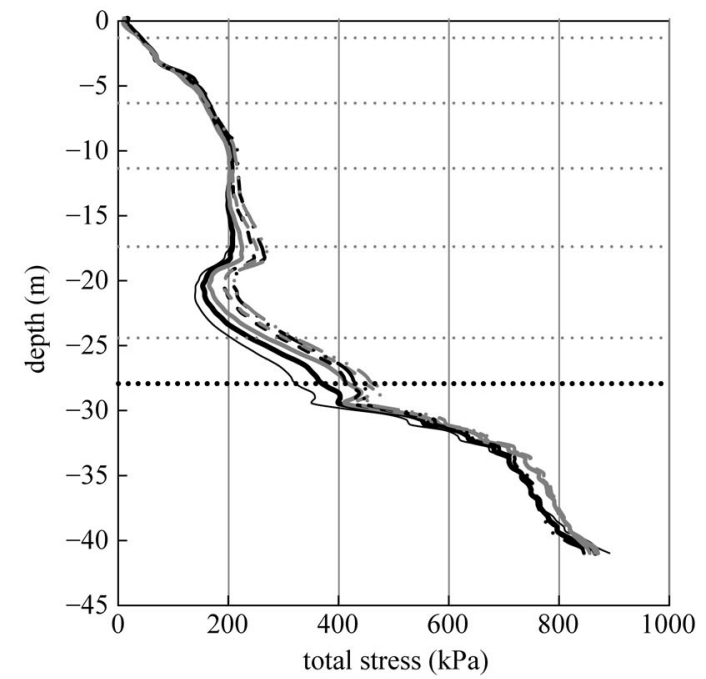

(b)



Fig. 5 Horizontal total stress applied to the diaphragm wall on the unexcavated side with variations in the thermal conductivity: (a) analysis B1: $\lambda \times 0.5$; (b) analysis A: original value; (c) analysis B2: $\lambda \times 2$.

increased from 15 to $60 \mathrm{kPa}$ when the thermal conductivity value increased from half the original value to twice the original value.

Figure 6 shows the horizontal relative displacement of the diaphragm wall when the displacement at the end of construction was set as the baseline. The maximum seasonal change in relative displacement every year was about $0.8 \mathrm{~mm}$ for analysis B2, and $0.3 \mathrm{~mm}$ for analysis B1. This seasonal change in the relative displacement of diaphragm wall was caused by two factors: thermally induced changes in the soil volume which push the wall toward the excavation side in summer and toward the unexcavated side in winter, and thermally induced bending of the thermo-active diaphragm wall which pushed the wall toward the unexcavated side in summer and toward the excavation side in winter. A change of conductivity influenced the temperature distribution in the soil significantly and thus led to the seasonal change in soil volume. With an increase in conductivity, the soil at the unexcavated side expanded more in summer and shrank more in winter, which exceeded the effect of the wall bending. Hence, the relative displacement shifted more 


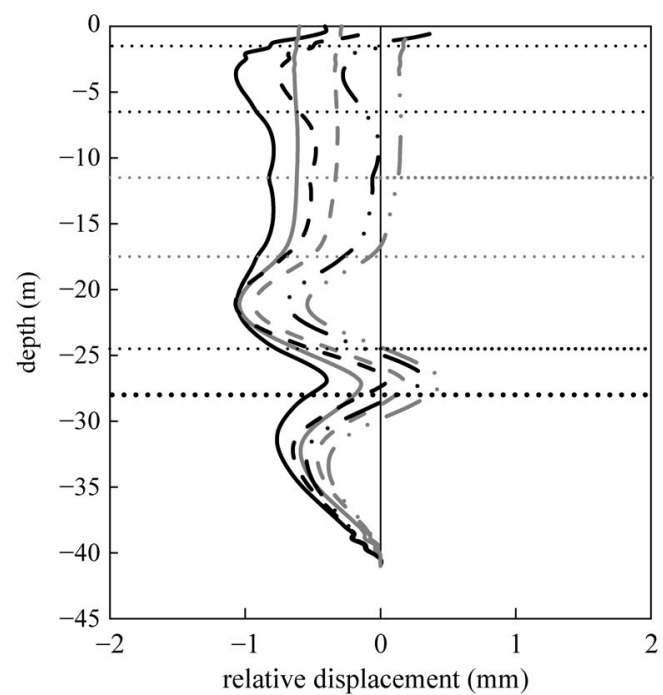

(a)



(c)



(b)



Fig. 6 Horizontal relative displacement of the diaphragm wall with variations in the thermal conductivity: (a) analysis B1: $\lambda \times 0.5$; (b) analysis A: original value; (c) analysis B2: $\lambda \times 2$.

toward the unexcavated side during the winter and moved toward the excavation side during the summer. Over the long-term, due to consolidation, the annual average displacement of the wall moved further to the unexcavated side when the thermal conductivity increased. With twice the thermal conductivity, the yearly average relative displacement was about $1 \mathrm{~mm}$, but with half the thermal conductivity, this yearly average displacement decreased to about $0.1 \mathrm{~mm}$.
Figure 7 shows the changes in bending moment with variations in the thermal conductivity of the soil, which show that variations in thermal conductivity have very little influence on the bending moment, especially above the base slab. On the other hand, some changes in bending moment under the base slab have been observed. In analysis B2, it was shown that the bending moment decreased about $100-200 \mathrm{kN} \cdot \mathrm{m}$ in winter compared to analysis B1, which is in accordance with the large change 


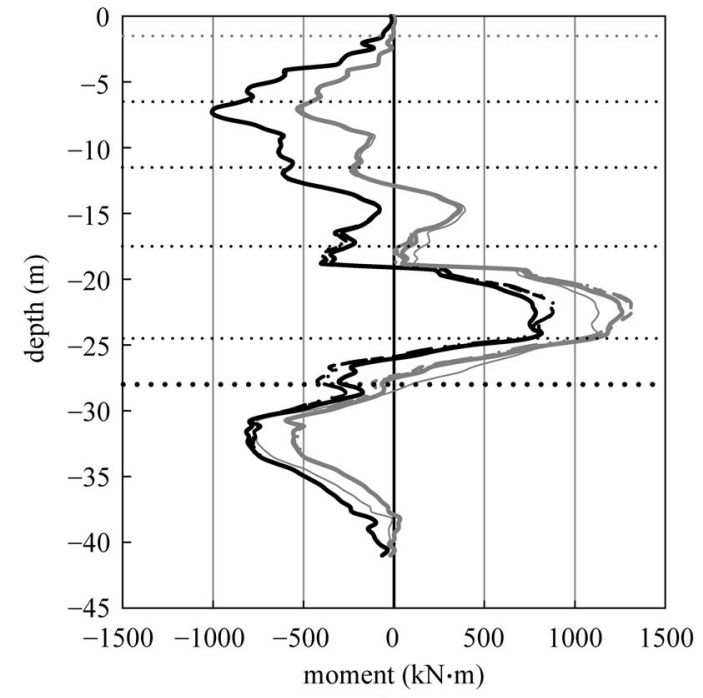

(a)

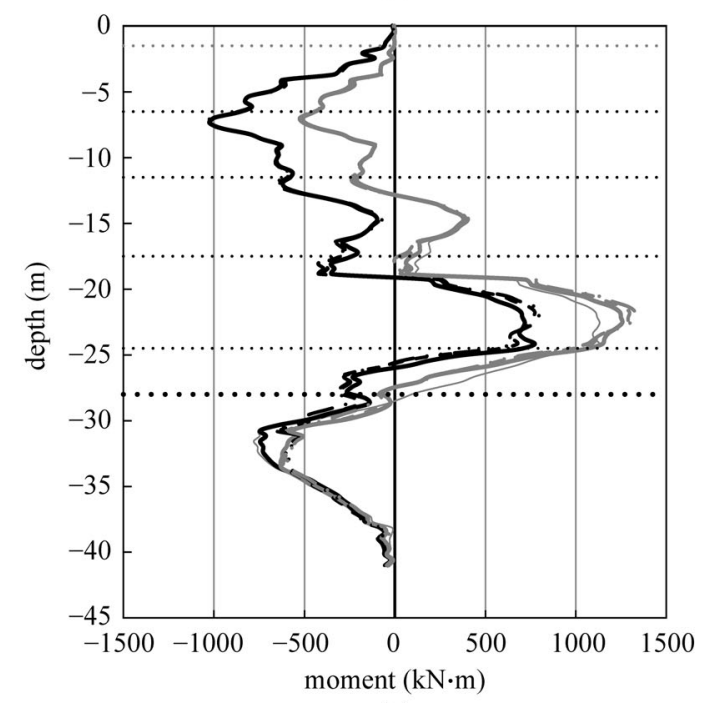

(c)

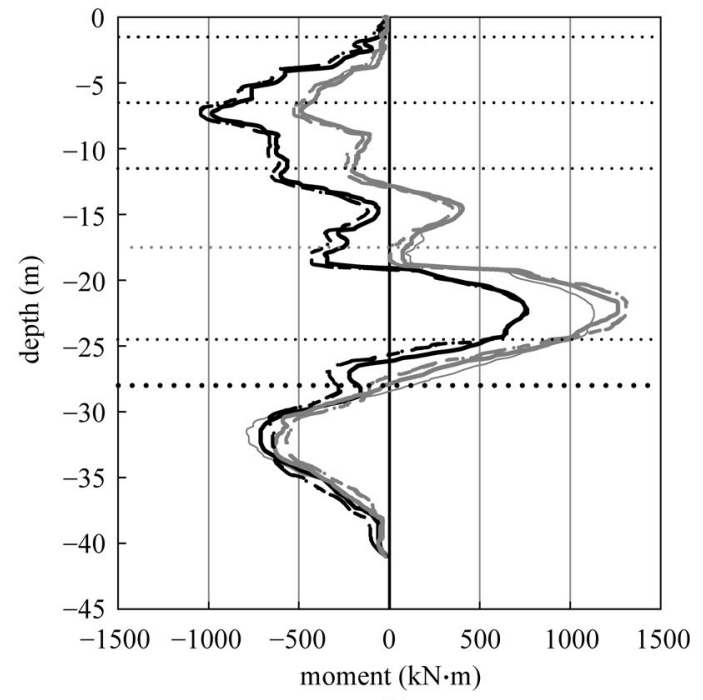

(b)

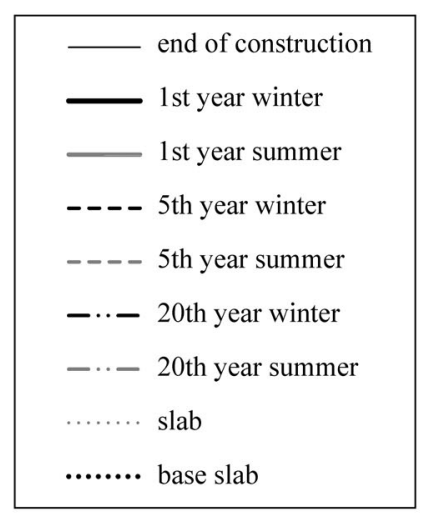

Fig. 7 Bending moment of the diaphragm wall with variations in the thermal conductivity: (a) analysis B1: $\lambda \times 0.5$; (b) analysis A: original value; (c) analysis $\mathrm{B} 2: \lambda \times 2$.

in the total stress under the base slab as shown in Fig. 5.

\subsection{Effects of permeability}

As shown in Fig. 8, changing the permeability of soil has a clear effect on the pore pressure distribution along the wall. With reduced permeability in analysis $\mathrm{C} 1$, the pore fluid migrated slowly within the soil skeleton, so the negative excess pore pressure only dissipated partly over the 20 -year period. The yearly average pore pressure at depth of $-21 \mathrm{~m}$ was about $50 \mathrm{kPa}$ after 20 years. On the other hand, the permeability has a large influence on the seasonal change in pore pressure. When applying 0.2 times the permeability coefficient, the change of pore pressure between summer and winter was about $80 \mathrm{kPa}$, much larger than that of the simulation with 5.0 times the 


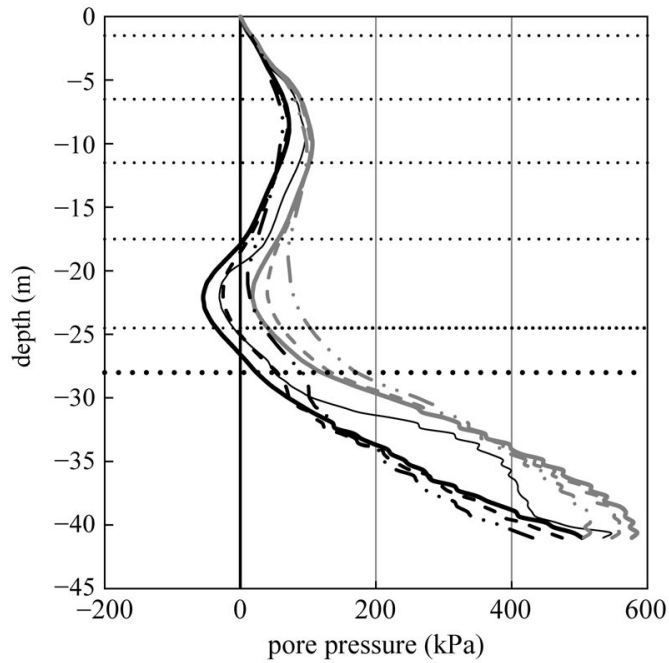

(a)

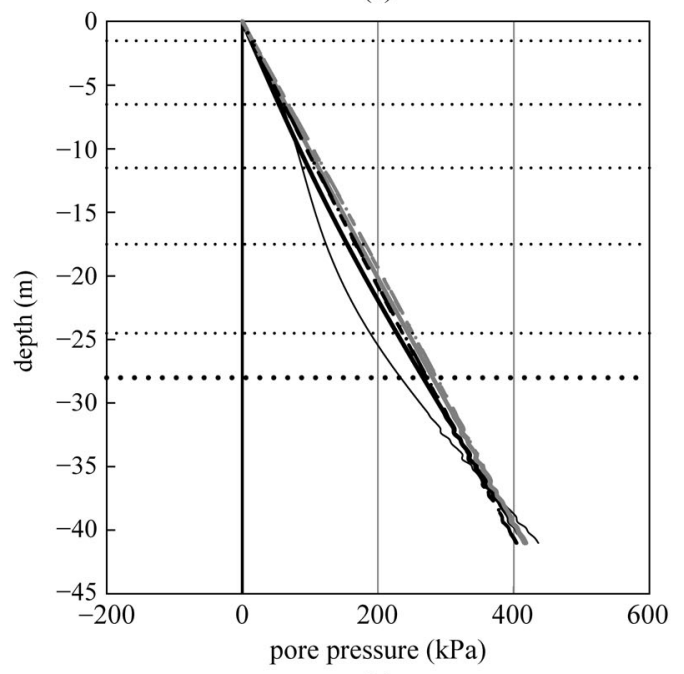

(c)

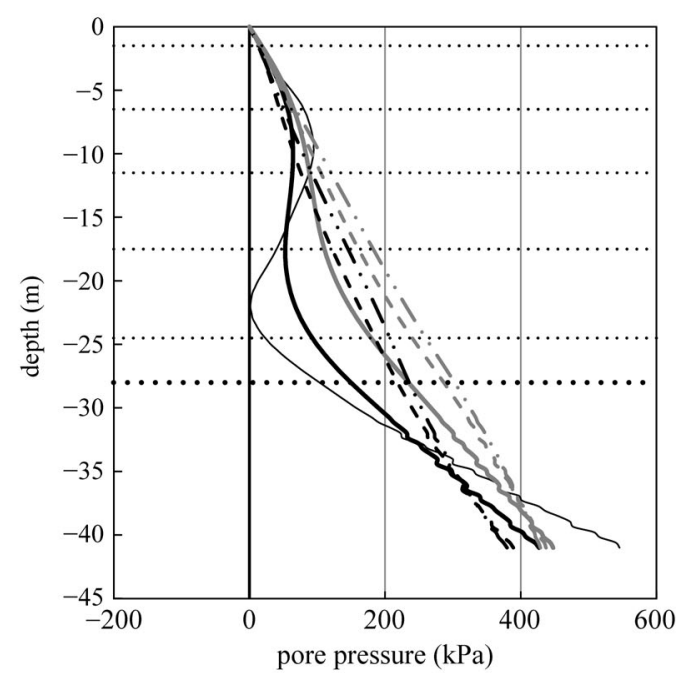

(b)

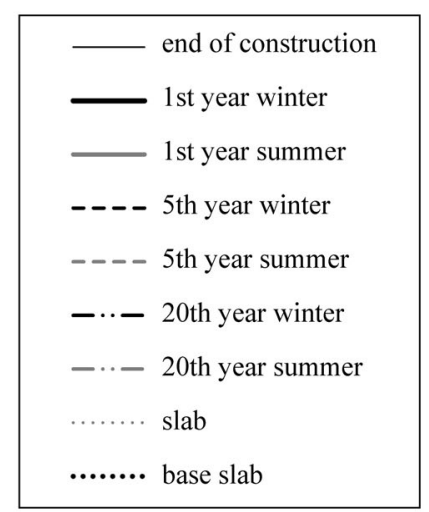

Fig. 8 Pore water pressure applied to the diaphragm wall on the unexcavated side with variations in the permeability of the soil: (a) analysis $\mathrm{C} 1: k \times 0.2$; (b) analysis A: original value; (c) analysis $\mathrm{C} 2: k \times 5$.

permeability coefficient in analysis $\mathrm{C} 2$. This is because the excess pressure caused by heating/cooling was trapped within the soil skeleton with low permeability. When the problem was simulated with 5.0 times the original permeability, the pore pressure profile observed in the model after 5 years was almost similar to the hydrostatic condition. The seasonal change in pore pressure is not obvious, which indicates that the excess pore pressure vanished in a very short time.

Figure 9 shows the horizontal total stress profiles along the unexcavated side of the wall. The permeability coefficient influenced two processes: long-term consolidation, and seasonal change in the total stress. First, the average annual horizontal total stress moved to the righthand side faster after 20 years with increased permeability, due to the acceleration of consolidation. After 20 years, the horizontal stress at depth of $-21 \mathrm{~m}$ was about $225 \mathrm{kPa}$ for the model with 5.0 times the permeability in analysis $\mathrm{C} 2$. However, when the permeability decreased to 0.2 times, the total stress at the same location was only about 


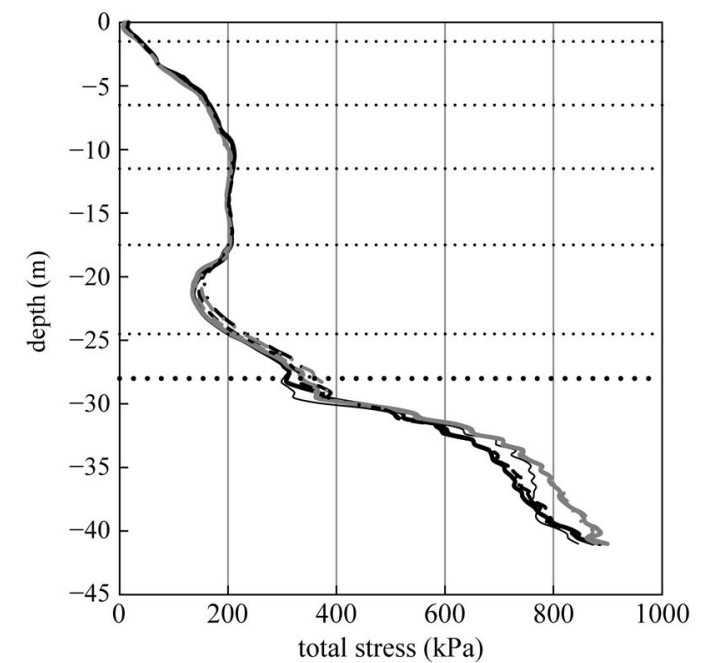

(a)

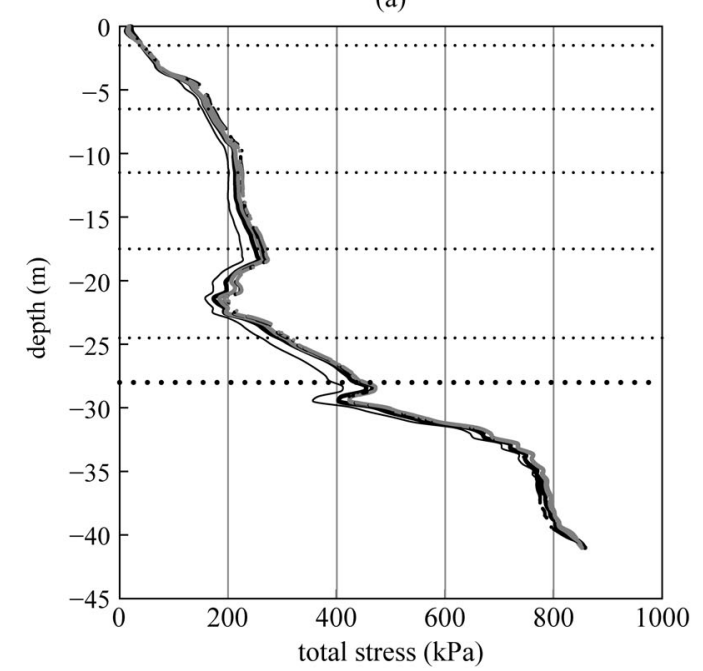

(c)

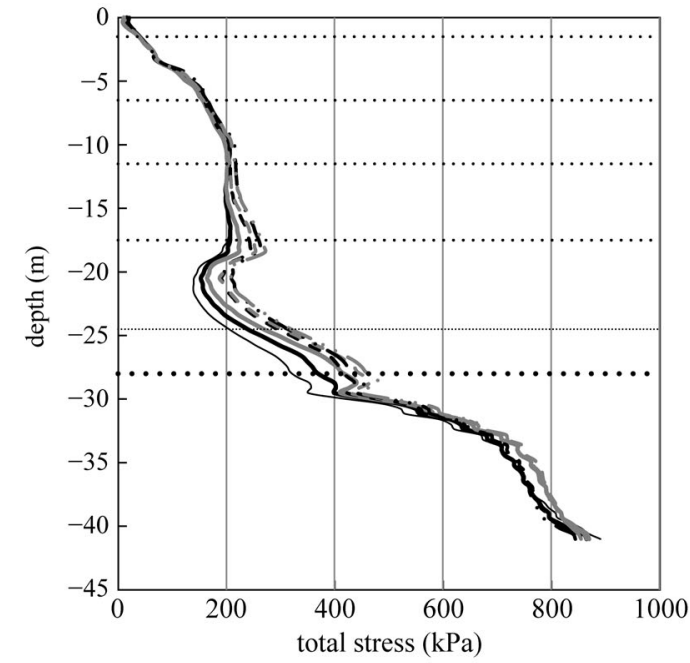

(b)

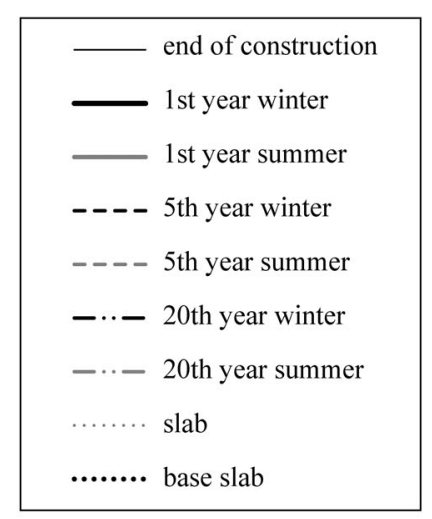

Fig. 9 Total stress applied to the diaphragm wall on the unexcavated side with variations in the permeability of the soil: (a) analysis C1: $k \times 0.2$; (b) analysis A: original value; (c) analysis $\mathrm{C} 2: k \times 5$.

$170 \mathrm{kPa}$. On the other hand, after 20 years, the seasonal changes in total stress every year for analyses $\mathrm{C} 1, \mathrm{~A}$, and C2 were 60,40 , and $20 \mathrm{kPa}$, respectively, as shown under the base slab in Fig. 9. That is because, when the permeability decreases, the pore fluid becomes trapped within the soil skeleton and the thermal expansion of the entrapped fluid induces stress upon the soil skeleton.

Figure 10 shows the wall relative displacement. The long-term wall movement was influenced by two factors due to the consolidation of two soil zones with construction-induced negative excess pore pressure. One was the pushing from the base slab due to the consolidation of the soil under the slab, and another was pushing by the soil on the unexcavated side due to the swelling of the soil on the right-hand side of the diaphragm wall. However, the seepage path length of the soil under the base slab was much longer than that on the unexcavated side. Hence, the consolidation of the soil under the base slab was much 


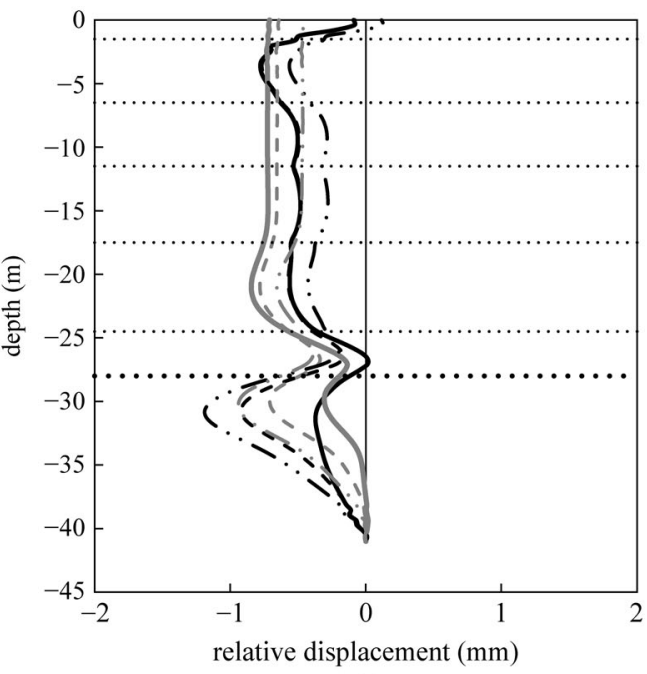

(a)

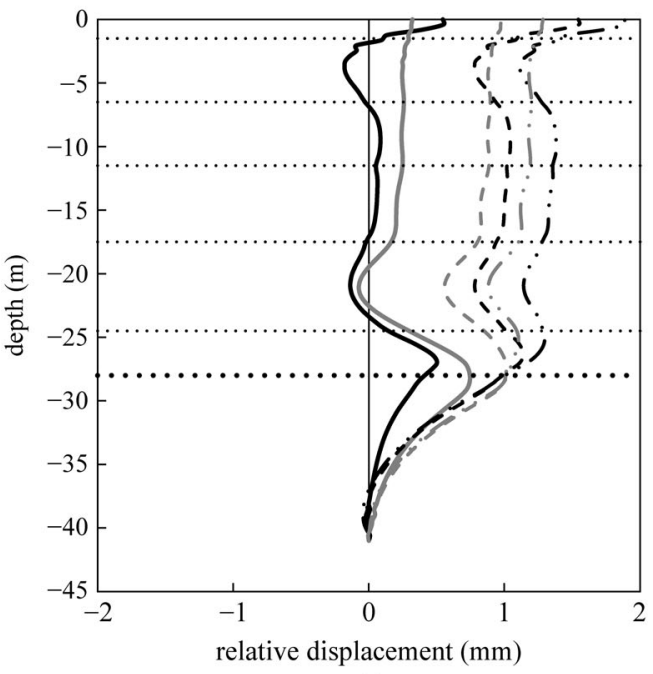

(c)

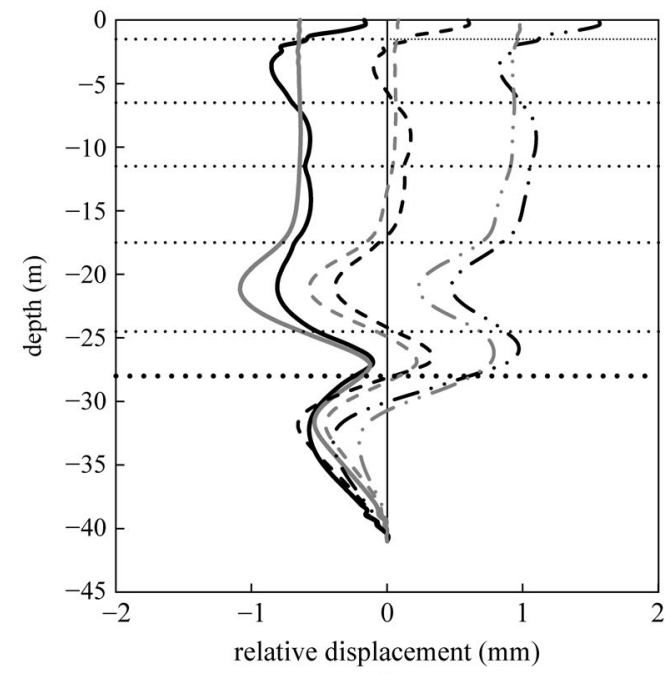

(b)

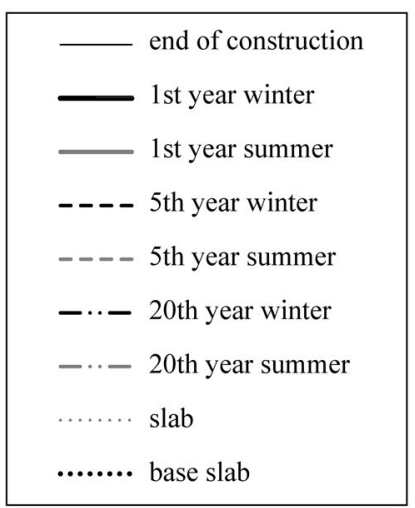

Fig. 10 Horizontal relative displacement of the diaphragm wall with variations in the permeability of the soil: (a) analysis C1: $k \times 0.2$; (b) analysis A: original value; (c) analysis $\mathrm{C} 2: k \times 5$.

more sensitive to the change of permeability coefficient than the consolidation on the unexcavated side. When the permeability coefficient decreased, the consolidation slowed down, so the effect of pushing by the base slab was less obvious. However, consolidation on the unexcavated side was less sensitive to permeability. For these reasons, when the permeability coefficient was 0.2 times that of analysis $\mathrm{C} 1$, the wall moved to the left side at the beginning, and then moved to the right-hand side slowly due to the delay of consolidation under the base slab. After 20 years, the wall only moved about $0.3 \mathrm{~mm}$ to the unexcavated side. In contrast, when the permeability coefficient was 5 times that of analysis $\mathrm{C} 2$, the wall moved to the right-hand side even at the beginning, 
especially at the position of the base slab. This result indicates that the pushing by the base slab was much prominent than the pushing by soil due to thermally induced expansion. After 20 years, this movement increased to about $1.2 \mathrm{~mm}$.

Figure 11 shows that the bending moment distribution along the wall did not change much with the increase in permeability above the base slab. On the other hand, the maximum bending moment under the base slab in analysis $\mathrm{C} 2$ increased by about $50-100 \mathrm{kN} \cdot \mathrm{m}$ compared to analysis
$\mathrm{C} 1$, but obviously this limited change did not compromise the structural capacity.

\subsection{Thermal expansion coefficient of the concrete}

In this section, $0,1.0$, and 4 times the thermal expansion coefficients were used for comparison. Figure 12 shows the total horizontal stress applied to the diaphragm wall at the unexcavated side. It was shown that the differences in total stress between these three cases were very limited. The

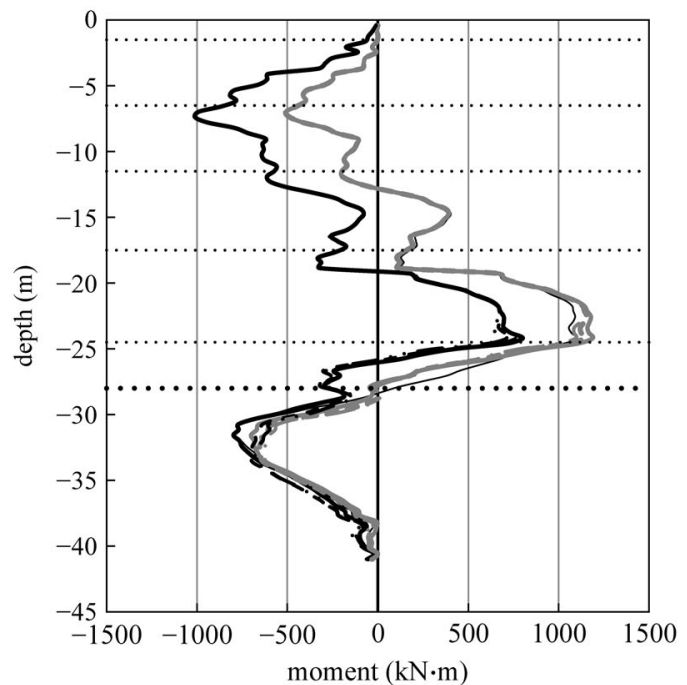

(a)



(c)

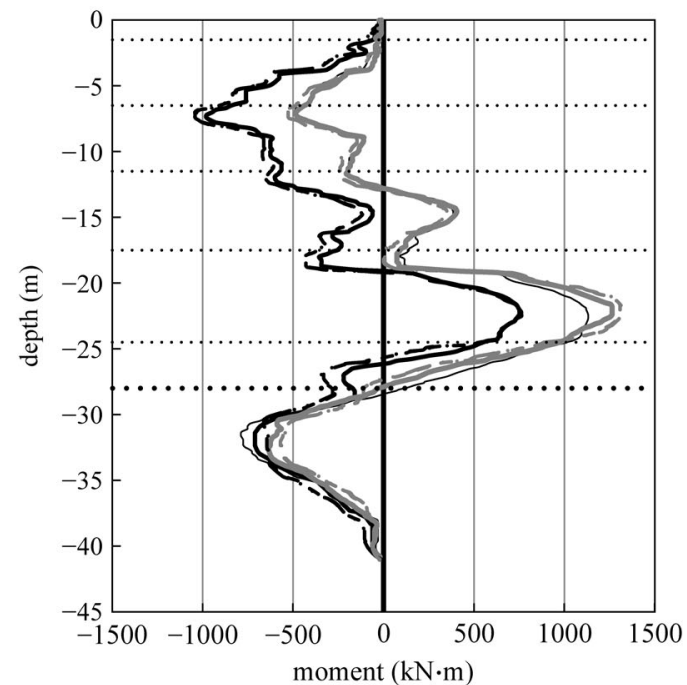

(b)

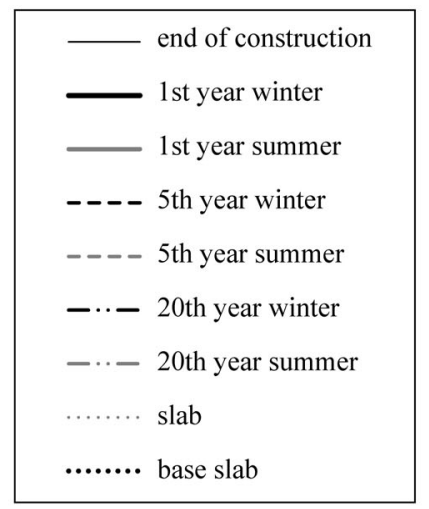

Fig. 11 Bending moment of the diaphragm wall with variations in the permeability of the soil: (a) analysis C1: $k \times 0.2$; (b) analysis A: original value; (c) analysis $\mathrm{C} 2: k \times 5$. 


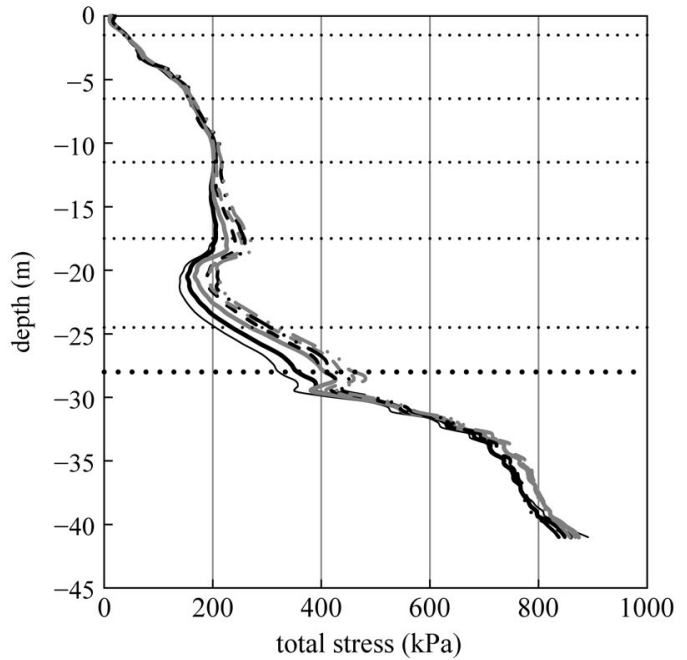

(a)

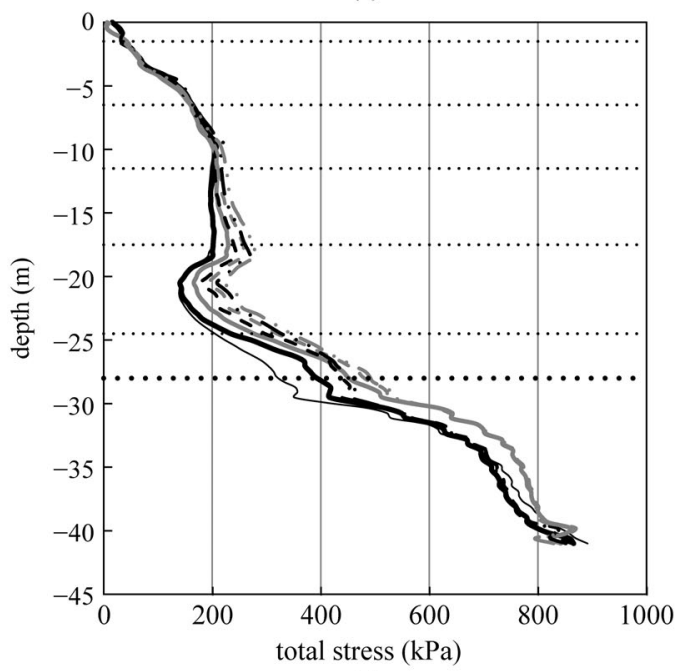

(c)

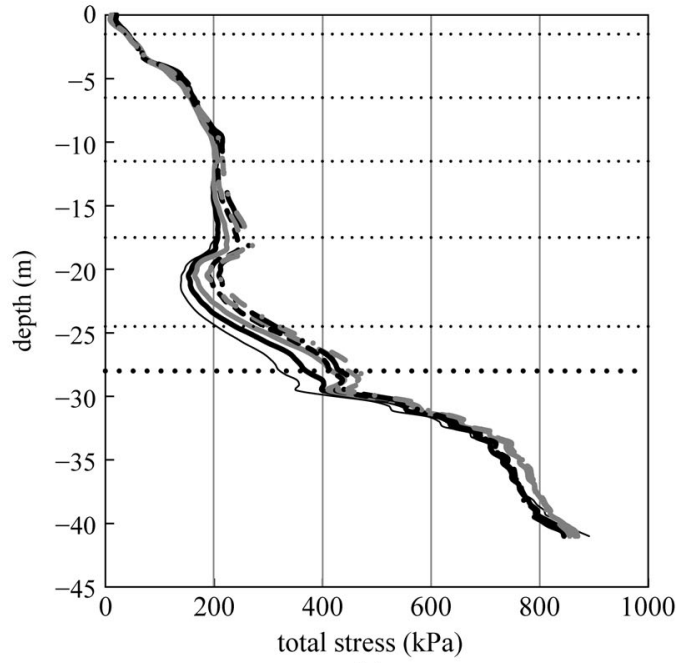

(b)

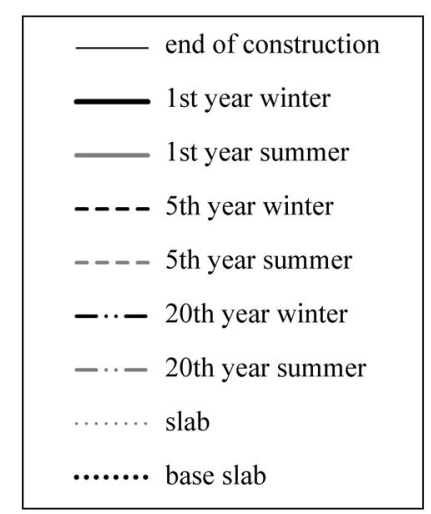

Fig. 12 Horizontal total stress applied on the diaphragm wall on the unexcavated side with variations in the thermal expansion coefficient of concrete: (a) analysis D1: $\alpha_{\text {con }} \times 0$; (b) analysis A: original value; (c) analysis D2: $\alpha_{\text {con }} \times 4$.

seasonal change in total stress was caused mainly by two factors: the thermally induced expansion and shrinkage in the soil, and the thermally induced bending of the diaphragm wall. Hence, in this parametric study, the small difference in total horizontal stress between analyses D1, A, and D2 indicates that the movement of the diaphragm wall had a lesser influence on the total stress compared to the thermally induced expansion and shrinkage in the soil.

Figure 13 shows the horizontal relative displacement profile of the diaphragm wall with different thermal expansion coefficients of the concrete. The seasonal change in displacement during operation of the GSHP with zero expansion of the concrete was caused by pushing from the soil due to thermally induced expansion only. During the summer, the wall moved to the left, and in winter, the wall moved to the right. A similar change occurred when applying the normal thermal expansion coefficient to the concrete, which further indicates that the seasonal change in the wall relative displacement was more dependent on the thermally induced change in the soil volume on the unexcavated side. When the thermal 


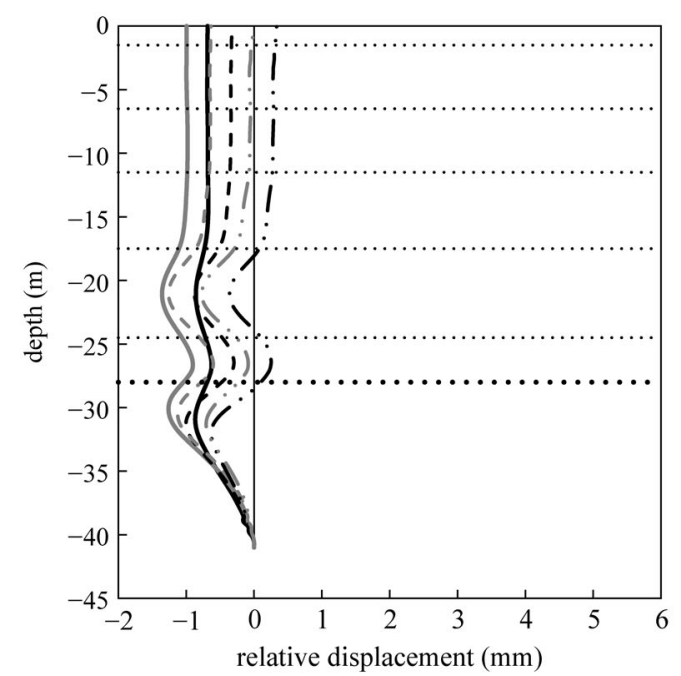

(a)

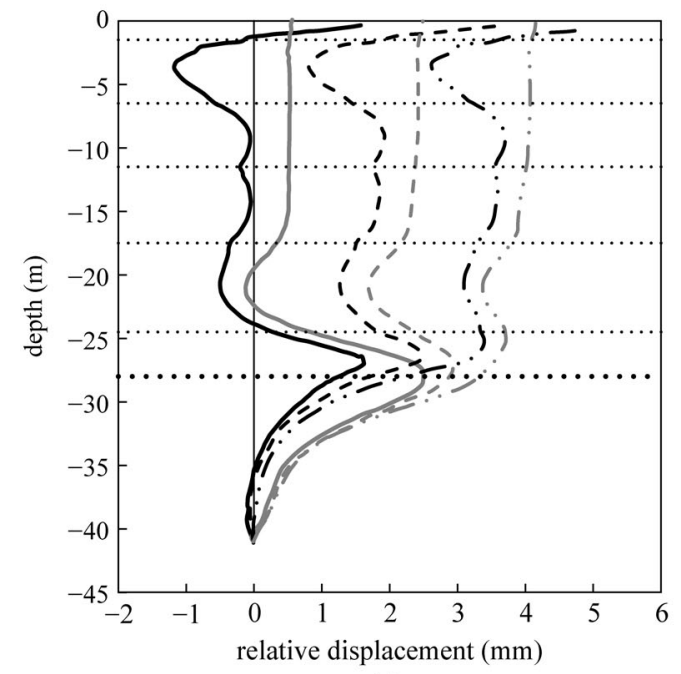

(c)

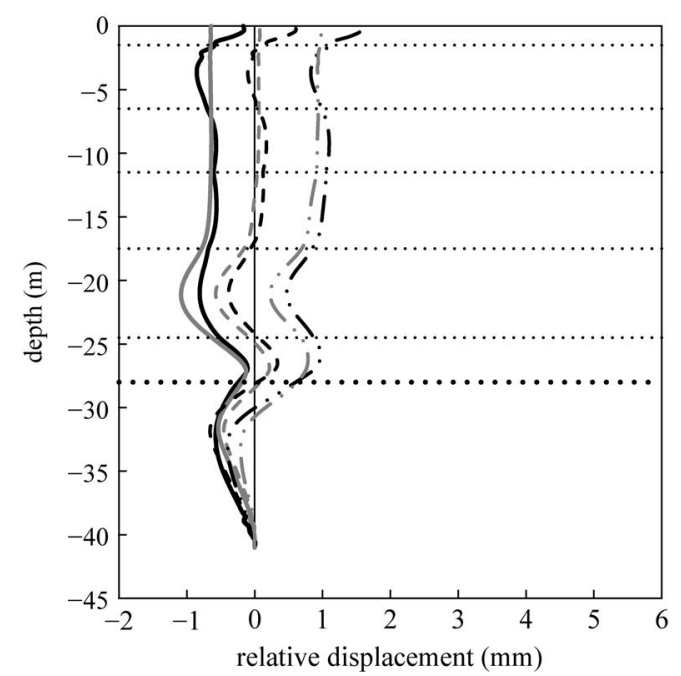

(b)

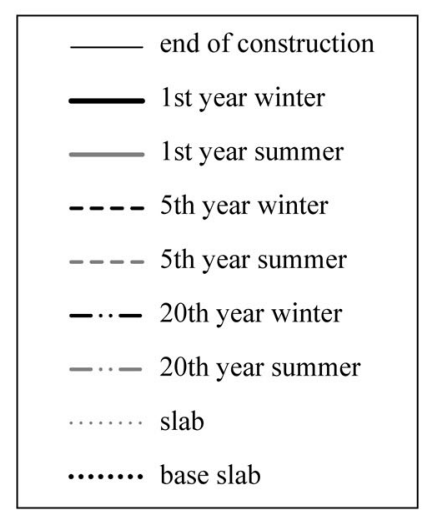

Fig. 13 Horizontal relative displacement of the diaphragm wall with variations in the thermal expansion coefficient of the concrete: (a) analysis D1: $\alpha_{\text {con }} \times 0$; (b) analysis A: original value; (c) analysis D2: $\alpha_{\text {con }} \times 4$.

expansion coefficient was not 0 , the wall bent toward the excavation side during the winter and bent back toward the unexcavated side during the summer. With 4 times the thermal expansion coefficient, this effect was enhanced. This is why there was a large fluctuation of about $0.6 \mathrm{~mm}$ between the summer cycle and the winter cycle, as shown in Fig. 13 with 4 times the thermal expansion coefficient. This seasonal change was only about $0.2 \mathrm{~mm}$ for the normal thermal expansion coefficient.

Figure 14 shows the bending moment of the diaphragm wall. With 4 times the thermal expansion coefficient, the maximum seasonal change in bending moment was about $2000 \mathrm{kN} \cdot \mathrm{m}$. But when the thermal expansion coefficient was zero, the variation in the bending moment was negligible, which is purely due to the change in earth pressure applied to the diaphragm wall. Therefore, the thermally induced change in earth pressure did not affect the structural performance significantly in the GSHP operation phase of the thermo-active diaphragm wall. The change in bending moment was mainly governed by 


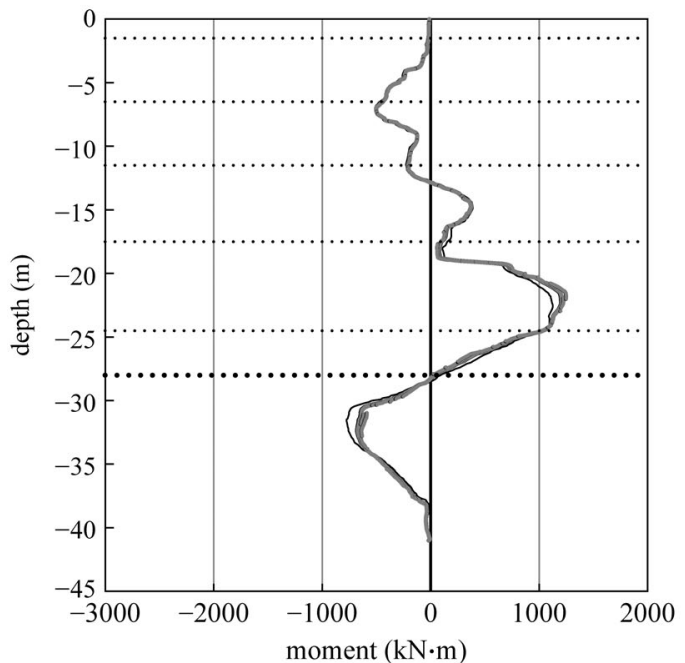

(a)

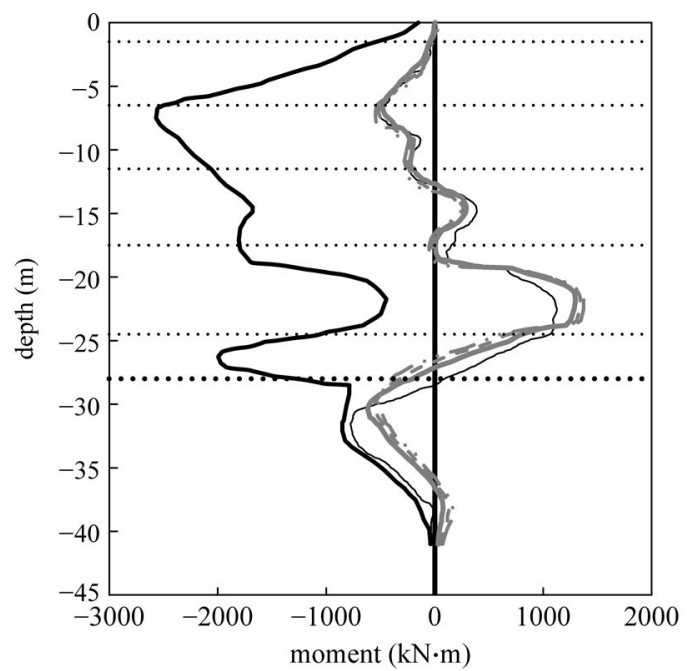

(c)

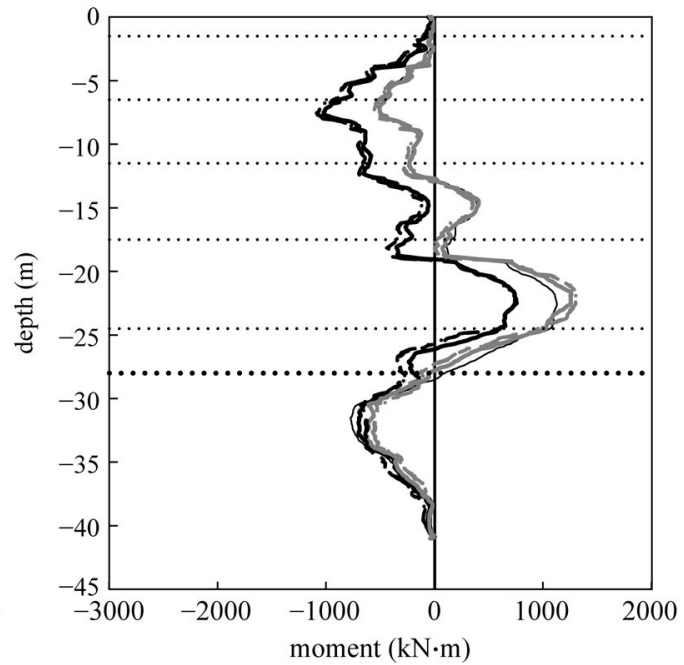

(b)



Fig. 14 Bending moment of the diaphragm wall with variations in the thermal expansion coefficient of the concrete: (a) analysis D1: $\alpha_{\text {con }} \times 0$; (b) analysis A: original value; (c) analysis D2: $\alpha_{\text {con }} \times 4$.

the unevenly distributed temperature in the wall, and the thermally induced volumetric change of the concrete. This phenomenon occurred when one side of the wall was exposed to the warm station temperature and the other half of the wall on the unexcavated side was cooled by the coolant in the buried pipe.

\section{Conclusions}

In this paper, a series of 2D THM coupling analyses was performed on the thermo-active diaphragm wall. The thermal operation of the thermo-active diaphragm wall caused changes in temperature, pore pressure, and total 
stress in the soil. These, in turn, caused displacements of the diaphragm wall and variations in the bending moments. Several conclusions are listed below.

1) When a higher thermal conductivity was assigned to the soil model, a greater area around the wall was influenced by the temperature change, and thus more expansion and shrinkage of soil occurred from heating and cooling, respectively. The total stress in the summer increased more when the thermal conductivity of the soil was higher, and thus the seasonal change in total stress increased from 15 to $60 \mathrm{kPa}$ when the thermal conductivity value increased from 0.2 times the original value to 5 times the original value.

2) Soil permeability has a large effect on the seasonal change of pore pressure. When 0.2 times the original permeability coefficient was applied, the seasonal change in pore pressure between summer and winter increased from 50 to about $80 \mathrm{kPa}$. With lower permeability, the soil behavior was closer to that under undrained conditions. As the permeability increased, the there was less change in pore pressure due to partial drainage, but more ground movement occurred.

3) The soil under the slab consolidated with time through dissipation of the positive excess pore pressure that developed due to the building load. Whereas the soil on the unexcavated side swelled with time from the dissipation of negative excess pore pressure that developed from movement of the wall. In the first 5 years of operation, the former was more sensitive to the change of permeability than the latter because of the difference in the drainage length. Hence, this in turn resulted in different wall movements depending on the soil permeability.

4) The thermal expansion of the wall concrete had a significant effect on the wall performance. In the case with the original thermal expansion coefficient, the maximum seasonal change in bending moment was about $300 \mathrm{kN} \cdot \mathrm{m}$. When the value increases to 4 times the original thermal expansion coefficient, this seasonal change increased to $1600 \mathrm{kN} \cdot \mathrm{m}$. However, when the thermal expansion coefficient was zero, the variation in bending moment was purely due to the change in earth pressure applied to the diaphragm wall, which was very limited. Therefore, the thermally induced change in earth pressure did not affect the structural performance significantly. The change in bending moment was mainly governed by the temperature differential and uneven thermal expansion/shrinkage across the wall.

Acknowledgements This research work was part of the Centre for Smart Infrastructure and Construction at University of Cambridge. We thank Professor Kenichi Soga, (UC Berkeley) for advice and help that greatly improved the research results.

Open Access This article is licensed under a Creative Commons Attribution 4.0 International License, which permits use, sharing, adaptation, distribution and reproduction in any medium or format, as long as you give appropriate credit to the original author(s) and the source, provide a link to the Creative Commons licence, and indicate if changes were made.

The images or other third party material in this article are included in the article's Creative Commons licence, unless indicated otherwise in a credit line to the material. If material is not included in the article's Creative Commons licence and your intended use is not permitted by statutory regulation or exceeds the permitted use, you will need to obtain permission directly from the copyright holder.

To view a copy of this licence, visit http://creativecommons.org/licenses/ by/4.0\%.

\section{Reference}

1. Brandl H. Energy foundations and other thermo-active ground structures. Geotechnique, 2006, 56(2): 81-122

2. Suckling T P, Smith P. Environmentally friendly geothermal piles at Keble College. In: Proceedings of the 9th International Conference on Piling and Deep Foundations. Nice: Deep Foundations Institute, 2002, 1016: 8-15

3. Laloui L, Di Donna A. Understanding the behaviour of energy geostructures. Proceedings of the Institution of Civil Engineers-Civil Engineering, 2011, 164(4): 184-191

4. Amis T, Robinson C, Wong S. Integrating geothermal loops into the diaphragm walls of the Knightsbridge Palace Hotel project. In: EMAP-Basements and Underground Structures. 2010

5. Bourne-Webb P J, Amatya B, Soga K, Amis T, Davidson C, Payne P. Energy pile test at Lambeth College, London: Geotechnical and thermodynamic aspects of pile response to heat cycles. Geotechnique, 2009, 59(3): 237-248

6. Bourne-Webb P J. Observed response of energy geostructures. Energy Geostructures: Innovation in underground engineering, 2013: 45-77

7. Bourne-Webb P J, Bodas Freitas T M, Freitas Assunção R M. Soilpile thermal interactions in energy foundations. Geotechnique, 2016, 66(2): 167-171

8. Bourne-Webb P J, Bodas Freitas T M, da Costa Gonçalves R A. Thermal and mechanical aspects of the response of embedded retaining walls used as shallow geothermal heat exchangers. Energy and Building, 2016, 125: 130-141

9. Amatya B L, Soga K, Bourne-Webb P J, AMIS T. Thermomechanical behaviour of energy piles. Géotechnique, 2012, 62(6): 503-519

10. Knellwolf C, Peron H, Laloui L. Geotechnical analysis of heat exchanger piles. Journal of Geotechnical and Geoenvironmental Engineering, 2011, 137(10): 890-902

11. Suryatriyastuti M E, Mroueh H, Burlon S. A load transfer approach for studying the cyclic behaviour of thermo-active piles. Computers and Geotechnics, 2014, 55: 378-391

12. Dupray F, Laloui L, Kazangba A. Numerical analysis of seasonal heat storage in an energy pile foundation. Computers and Geotechnics, 2014, 55: 67-77

13. Ozudogru T Y, Olgun C G, Senol A. 3D numerical modeling of vertical geothermal heat exchangers. Geothermics, 2014, 51: 312324

14. Ma X, Qiu G, Grabe J. Numerical simulation of an energy pile using thermo-hydro-mechanical coupling and a visco-hypoplastic model. 
Geotechnical Engineering Journal of the SEAGS and AGSSEA, 2014, 45(2): 12-16

15. Di Donna A, Dupray F, Laloui L. Numerical study of the heatingcooling effects on the geotechnical behaviour of energy piles. In: Coupled Phenomena in Environmental Geotechnics. Torino: CRC Press, 2013: 475-482

16. Gawecka K A, Taborda D M G, Potts D M, Cui W, Zdravković L, Haji Kasri M S. Numerical modelling of thermo-active piles in London Clay. Proceedings of the Institution of Civil EngineersGeotechnical Engineering, 2017, 170(3): 201-219

17. Rotta Loria A F, Laloui L. The interaction factor method for energy pile groups. Computers and Geotechnics, 2016, 80: 121-137

18. Rotta Loria A F, Vadrot A, Laloui L. Effect of non-linear soil deformation on the interaction among energy piles. Computers and Geotechnics, 2017, 86: 9-20

19. Rui Y, Yin M. Investigations of pile-soil interaction under thermomechanical loading. Canadian Geotechnical Journal, 2018, 55(7):
1016-1028

20. Rui Y, Soga K. Thermo-hydro-mechanical coupling analysis of a thermal pile. Proceedings of the Institution of Civil EngineersGeotechnical Engineering, 2019, 172(2): 155-173

21. Zhuang X, Huang R, Liang C, Rabczuk T. A coupled thermo-hydromechanical model of jointed hard rock for compressed air energy storage. Mathematical Problems in Engineering, 2014, 2014: 179169

22. Sterpi D, Coletto A, Mauri L. Investigation on the behaviour of a thermo-active diaphragm wall by thermo-mechanical analyses. Geomechanics for Energy and the Environment, 2017, 9: 1-20

23. Rui Y, Yin M. Thermo-hydro-mechanical coupling analysis of a thermo-active diaphragm wall. Canadian Geotechnical Journal, 2018, 55(5): 720-735

24. Rui Y, Garber D, Yin M. Modelling ground source heat pump system by an integrated simulation programme. Applied Thermal Engineering, 2018, 134: 450-459 